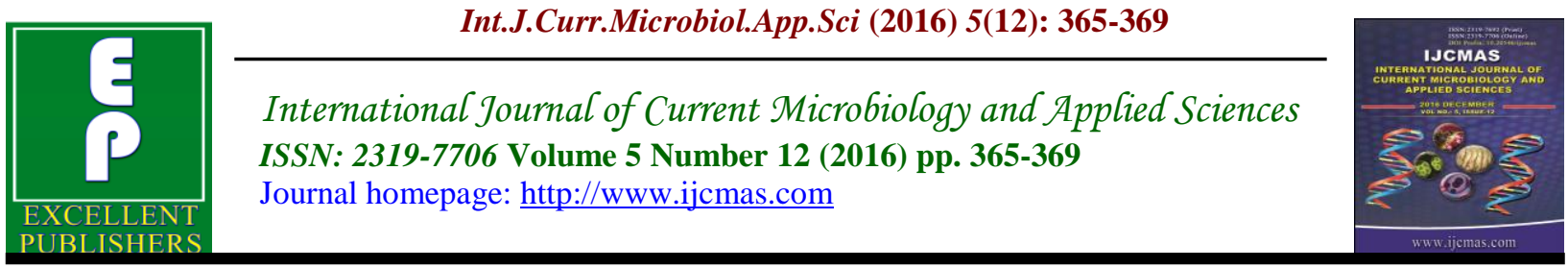

Original Research Article

http://dx.doi.org/10.20546/ijcmas.2016.512.039

\title{
Degradation of Nicotine by the Resident Flora of the Oral Cavity in Tobacco Consumers
}

\author{
Pranita A. Gulhane*, Ashok V. Gomashe and Rucha Parsodkar \\ Department of Microbiology, S.S.E.S.A's Science College, Congress Nagar, \\ Nagpur (Ms) India-440012 \\ *Corresponding author
}

Keywords

Nicotine

Degrading

Oral Bacteria, Lactobacillus sp.

Article Info

Accepted:

19 November 2016

Available Online:

10 December 2016
A B S T R A C T

Nicotine degradation by micro-organisms has received increasing attention in the past 50 years because microorganisms have the potential to reduce nicotine levels in tobacco. As an environment-friendly treatment, microbial degradation of nicotine has been considered as a promising method due to its low cost and high efficiency. However, the current understanding of nicotine metabolism in microorganisms is poor. Therefore aim of the present investigation was to isolate nicotine degrading bacteria from oral cavity in tobacco chewers and to study its effect on nicotine degradation. Oral swab samples were collected from tobacco consumers. In the present study the bacteria identified was found to be Lactobacillus sp. The inhibitory concentration of nicotine for the nicotine degrading bacteria was studied. It was observed that the increased concentration of nicotine in the nicotine liquid medium was inhibitory to the growth of bacteria in the medium. It was concluded that Lactobacillus sp. present in mouth can utilize and breakdown the nicotine. But it should also be taken into consideration that increased amount of nicotine has been found to be inhibitory for these nicotine utilizing bacteria as well.

\section{Introduction}

Tobacco is a product prepared from the leaves of tobacco plants. Chewing tobacco is a serious health risk that can cause severe oral diseases and introduce pathogenic bacteria into the oral cavity. Tobacco is an addictive drug that is harmful to one's health and its use could possibly lead to death (Antolin, 2006). Consumption of tobacco leads to halitosis, stained teeth, dental restorations and serious diseases such as oral cancer (Patel et al., 2004), gingivitis, periodontitis (Scott and Singer, 2004), melanosis (increased pigmentation on the cheeks and gums), and leukoplakia (white patches or plaques on the lining of the oral mucosa) (Srinivasan and Jewel, 2001).

Nicotine, a principal pyridine alkaline in tobacco plants, is notorious for its significant contribution to tobacco addiction. However, nicotine is very toxic to humans because it is easily absorbed in the body; its hydrophilic nature contributes to the environmental contamination (Holmstedt, 
1988; Liu et al., 2014). Nicotine can penetrate biological membranes and the blood-brain barrier easily to exert its effects (Schievelbein, 1982). Nicotine is not a direct cause of most tobacco smoking-related diseases, but it is highly addictive (Benowitz et al., 1999). Currently, regulatory strategies to control the tobacco induced disease epidemic are very much focused on nicotine.

Nicotine degradation by micro-organisms has received increasing attention in the past 50 years because microorganisms have the potential to reduce nicotine levels in tobacco (Civilini et al., 1997; Wang et al., 2004). Many bacteria capable of utilizing nicotine have been isolated and characterized (Brandsch, 2006). As an environmentfriendly treatment, microbial degradation of nicotine has been considered as a promising method due to its low cost and high efficiency. However, the current understanding of nicotine metabolism in micro-organisms is poor. Therefore aim of the present investigation was to isolate nicotine degrading bacteria from oral cavity in tobacco chewers and to study its effect on nicotine degradation.

\section{Materials and Methods}

\section{Isolation of bacteria from oral cavity of tobacco chewers}

Oral samples (mouth swabs) were collected from tobacco chewers, using sterilized cotton buds. The collected swab samples were inoculated in liquid medium containing $1 \mathrm{gm} /$ litre nicotine at $30^{\circ} \mathrm{C}$ with shaking at $120 \mathrm{rpm}$ in an incubator. The liquid culture medium was a minimal medium containing (per litre) $13.3 \mathrm{~g} \quad \mathrm{~K}_{2} \mathrm{HPO}_{4} .3 \mathrm{H}_{2} \mathrm{O}, 4 \mathrm{~g}$ $\mathrm{KH}_{2} \mathrm{PO}_{4}, 0.2 \mathrm{~g} \mathrm{MgSO}_{4} .7 \mathrm{H}_{2} \mathrm{O}$ and $0.5 \mathrm{ml}$ trace elements solution. The trace elements solution contained (per litre of $0.1 \mathrm{M} \mathrm{HCl}$ ) 0.05 g $\mathrm{CaCl}_{2} .2 \mathrm{H}_{2} \mathrm{O}, 0.05$ g $\mathrm{CuCl}_{2} .2 \mathrm{H}_{2} \mathrm{O}$,
$0.008 \mathrm{~g} \mathrm{MnSO}_{4} \cdot \mathrm{H}_{2} \mathrm{O}, 0.004 \mathrm{~g} \mathrm{FeSO}_{4} .7 \mathrm{H}_{2} \mathrm{O}$, $0.1 \mathrm{~g} \mathrm{ZnSO} 4,0.1 \mathrm{~g} \mathrm{Na}_{2} \mathrm{MoO} 4.2 \mathrm{H}_{2} \mathrm{O}$ and $0.05 \mathrm{~g} \mathrm{Na}_{2} \mathrm{WO}_{4} \cdot 2 \mathrm{H}_{2} \mathrm{O}$. Nicotine was added to the medium after filter-sterilization. After bacterial growth was observed, the culture was used as an inoculum and transferred twice. The final culture $(0.1 \mathrm{ml})$ was serially diluted and spread onto agar plates containing nicotine. After 2 days, colonies began to appear on plates incubated at $30^{\circ} \mathrm{C}$. The colonies were picked and streaked to purity on nicotine agar plates. The isolated bacteria were identified on the basis of morphological, cultural and biochemical characteristics (Wang et al., 2004).

\section{Inhibitory Effect of Different Nicotine Concentration on Isolated Bacteria}

Two sets of test tubes containing liquid medium with increasing nicotine concentration were used with 8 test tubes in each set. One set was inoculated with the isolated bacteria and other was kept uninoculated. In each set one tube containing the standard concentration of nicotine was considered as Blank. Both the set of test tubes were incubated for 2 days at $30^{\circ} \mathrm{C}$. After 2 days, the tubes were observed for turbidity and compared to the uninoculated tube of the respective concentrations. Optical density was taken at $620 \mathrm{~nm}$. The optical densities of the inoculated tubes were compared with optical densities of the uninoculated tubes to observe the effect of increasing concentration of nicotine on the bacteria (Kumari and Thangavel, 2016).

\section{Results and Discussion}

A nicotine-degrading bacterium was isolated from oral cavity samples obtained from tobacco chewers in Nagpur. On the basis of identification Lactobacillus spp. was isolated. Saliva is the first biological fluid 
that is exposed to tobacco which is responsible for the changes in salivary $\mathrm{pH}$. The bacteria could use nicotine as the sole carbon, nitrogen and energy source (Mujahid et al., 2014). It was reported that
Lactobacillus sp. were utilizing nicotine at maximum of $\mathrm{pH} 7.0$ and sudden increase in $\mathrm{pH}$ indicates nicotine degradation (Chaudhary et al., 2007).

Table.1 Inhibitory Effect of Nicotine on Nicotine Degrading Bacteria

\begin{tabular}{|c|c|c|}
\hline $\begin{array}{c}\text { Nicotine } \\
\text { Concentration } \\
\text { (g/litre) }\end{array}$ & $\begin{array}{c}\text { Optical Density } \\
\text { (nm) of } \\
\text { Uninoculated tubes }\end{array}$ & $\begin{array}{c}\text { Optical Density } \\
\text { (nm) of } \\
\text { Inoculated tubes }\end{array}$ \\
\hline Blank & 0.0 & 0.0 \\
\hline 0.5 & 0.27 & 0.65 \\
\hline 1.0 & 0.46 & 0.80 \\
\hline 1.5 & 0.69 & 1.19 \\
\hline 2.0 & 0.93 & 1.26 \\
\hline 2.5 & 1.23 & 1.57 \\
\hline 3.0 & 1.44 & 1.69 \\
\hline 3.5 & 1.72 & 1.88 \\
\hline 4.0 & 1.89 & 1.92 \\
\hline
\end{tabular}

Fig.1 Inhibitory Effect of Nicotine on Nicotine Degrading Bacteria

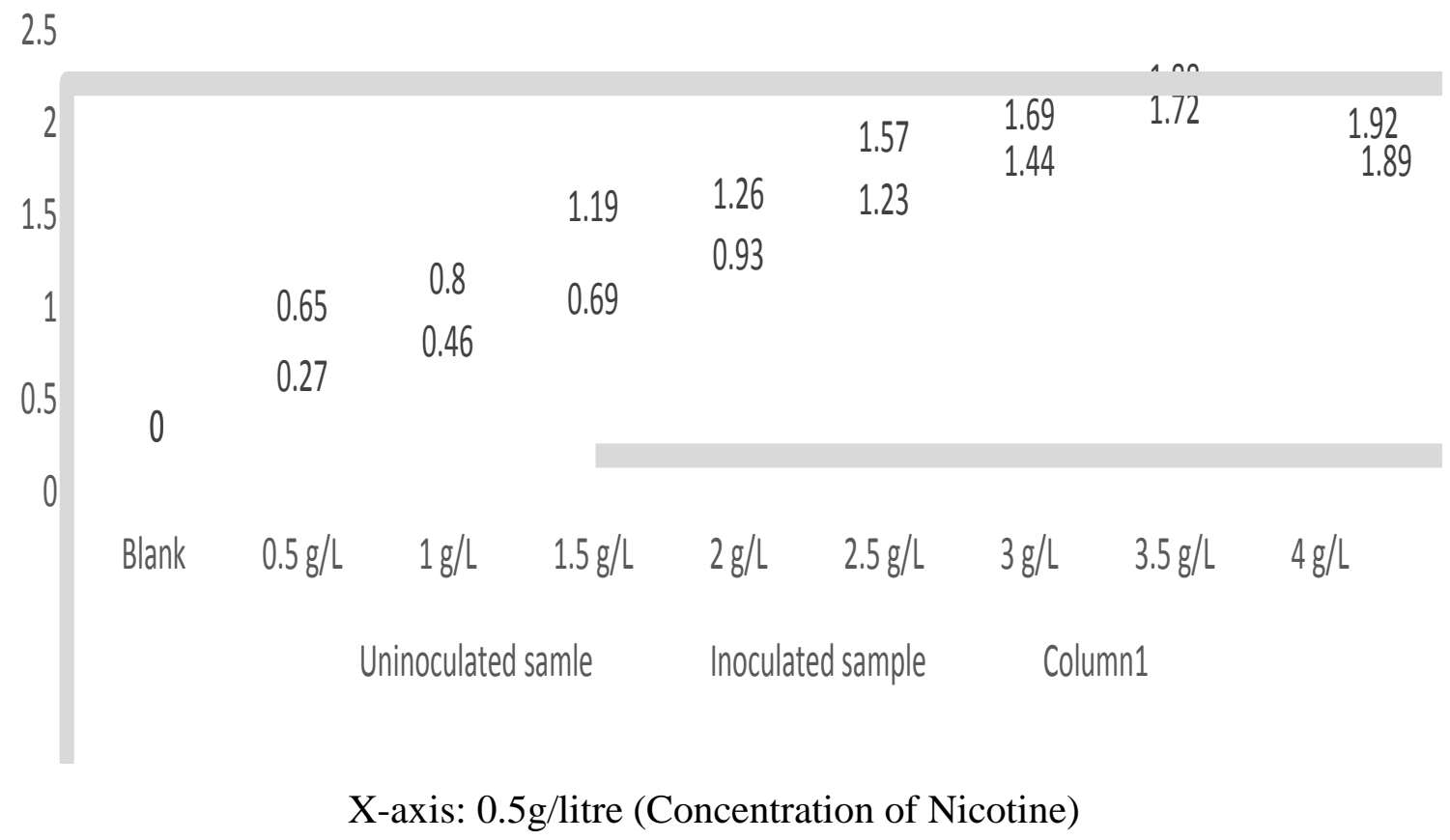


The liquid nicotine medium that was prepared and suspended into test tubes with increasing amount of nicotine was inoculated with the nicotine degrading bacteria that had been isolated from the mouth of tobacco chewers. The objective was to find the inhibitory concentration of nicotine for these nicotine degrading bacteria. Consequently, it was seen that the increased concentration of nicotine in the nicotine liquid medium, that is, concentration of more than $4 \mathrm{~g} /$ litre was toxic to the growth of bacteria in the medium (Table 1) (Figure 1). It was reported that Pseudomonas sp. and Arthrobacter carries the ability to breakdown nicotine into carbon, nitrogen and energy (Brandsch et $a l ., 1982)$. Nicotine utilizing organisms were also studied for nicotine degradation by some researchers (Haileiwei et al., 2008). In some studies normal oral flora organisms were isolated such as Staphylococcus sp., Streptococcus sp., Proteus sp., Pseudomonas sp. and Klebsiella sp. and reported that Pseudomonas sp. has the ability to degrade nicotine (Kumari and Thangavel, 2016).

In conclusion, it can be suggested from the present study that the microorganisms isolated from the oral swab of the tobacco consumers can utilize nicotine present in tobacco and also decrease the hazardous effect that nicotine has on human health after continuous consumption. The bacterium isolated was found to be the Lactobacillus sp.

It can thus be said that the presence of Lactobacillus sp. in the mouth is an advantage in itself. The utilization of nicotine by this Lactobacillus sp. is beneficial to the tobacco chewers, because a part of the nicotine in the tobacco is degraded in the mouth which might help in decreasing the risk associated with it. Thus it can be concluded that the species of Lactobacillus sp. present in mouth can utilize and breakdown the nicotine. But it should also be taken into consideration that increased amount of nicotine has been found to be inhibitory for these nicotine utilizing bacteria as well.

\section{References}

Antolin, K. 2006. Comparison of bacterial growth in the oral cavity between tobacco consumers and non-tobacco users. Saint Martin's University Biology J., 1: 175-184.

Benowitz, N.L., Perez-Stable, E.J., Fong, I., Modin, G., Herrera, B. and Jacob, P. 1999. Ethnic differences in Nglucuronidation of nicotine and cotinine. J. Pharmacol. Exp. Ther., 291: 1196-1203.

Brandsch, R. 2006. Microbiology and biochemistry of nicotine degradation. Appl. Microbiol. Biotechnol., 69: 493498.

Brandsch, R., Hinkkanen, A.E. and Decker, K. 1982. Plasmid mediated nicotine degradation in Arthrobacter oxidans. Arch. Microbiol., 132: 26-30.

Chaudhary, N., Qazi, J.I. and Gill, A. 1982. Isolation and optimization of tobacco decomposing Bacillus and Lactobacillus sp. Caspean J. Environ. Sci., 5: 45-49.

Civilini, M., Domenis, C., Sebastianutto, N. and de Berfoldi, M. 1997. Nicotine decontamination of tobacco agroindustrial waste and its degradation by micro-organisms. Waste Man Res., 15: 349-358.

Haileiwei, Liping, L., Zhenyuan, X.I.A., Shuo, L.I.U., Xingzhong, L.I.U. and Peigui, L.I.U. 2008. Characterization of a novel aerobic nicotine biodegrading strain of Pseudomonas putida. Ann. Microbiol., 58: 41-45. 
Holmstedt, B. 1988. The Pharmacology of Nicotine. In: McLean, VA editors. Toxicity of nicotine and related compounds. ICSU Symposium Series, 9, IRL Press.

Kumari, G. and Thangavel, M. 2016. Microbial Reduction of Nicotine and Effect on Oral Flora. European $J$. Pharmaceutical and Med. Res., 3(4): 315-321.

Liu, Y., Wang, L., Huang, K., Wang, W., Nie, X., Jiang, Y., Li, P., Liu, S., Xu, P. and Tang, H. 2014. Physiological and Biochemical Characterization of a Novel Nicotine-Degrading Bacterium Pseudomonas geniculata N1. Plos One, 9(1): 1-9.

Mujahid, M., Anushree, B. and Shobha, M. 2014. Salivery Levels of Cariogenic Streptococcus and Lactobacillus among Tobacco Abusers in Andhra Pradesh, India. Res. J. Pharmaceutical, Biol. Chem. Sci., 5(6): 521-530.

Patel, B.P., Upendra, R.M., Pankaj, S.M., Jayesh, P.A., Rakesh, R.M., Tina,
D.K. and Prabhudas, P.S. 2004. Study of tobacco habits and alterations in enzymatic antioxidant system in oral cancer. Oncol., 68: 511-519.

Schievelbein, H. 1982. Nicotine, resorption and fate. Pharmacol. Ther., 18: 233248.

Scott, D.A. and Singer, D.L. 2004. Suppression of overt gingival inflammation in tobacco smokersclinical and mechanistic considerations. Int. J. Dent. Hyg., 2: 104-110.

Srinivasan, M. and Jewell, S.D. 2001. Evaluation of TGT-alpha and EGFR expression in oral leukoplakia and oral submucous fibrosis by quantitative immune histochemistry. Oncol., 61: 284-292.

Wang, S.N., Xu, P., Tang, H.Z., Meng, J., Liu, X.L., Huang, J., Chen, H., Du, Y. and Blankespoor, H.D. 2004. Biodegradation and detoxification of nicotine in tobacco solid waste by a Pseudomonas sp. Biotechnol. Lett., 26: 1493-1496.

\section{How to cite this article:}

Pranita A. Gulhane, Ashok V. Gomashe and Rucha Parsodkar. 2016. Degradation of Nicotine by the Resident Flora of the Oral Cavity in Tobacco Consumers. Int.J.Curr.Microbiol.App.Sci. 5(12): 365-369. doi: http://dx.doi.org/10.20546/ijcmas.2016.512.039 